Kaaryn Cater

\title{
Small shifts, big changes: changing the story for students with Sensory Processing Sensitivity (SPS)
}

DOI 10.1515/ijtr-2016-0010

received September 2016; accepted November 2016
'In a gentle way, you can shake the world' Mahatma Gandhi

\begin{abstract}
It is my privilege to work as a tertiary learning advisor (TLA). Through my role I have had the opportunity to form unique relationships with students during individual consultations. This has enabled me to observe student behaviour, and the metacognitive strategies students use to negotiate the myriad challenges of tertiary study. I noticed trends in student behaviour that did not fit current literature on teaching and learning, and identified possible links between the observed student feelings of overwhelm, and sensory processing sensitivity (SPS) and highly sensitive people (HSP), the term used to describe humans with SPS. This paper examines the transformative journey I took in identifying the key indicators of SPS, firstly in myself, and then in my students. My burgeoning knowledge and reflection on and in my own practice provided self-scaffolding that enabled me to recognise and share the markers of SPS. My study 'Does an understanding of HSP help students who identify as Highly Sensitive People (HSP) to manage their learning?' found that HSP students unanimously rate the knowledge of SPS to be life-changing and empowering in managing life and study. All participants also believed that information about SPS should be made available to all in-coming students, and that tutors should be given training and resources in order to better support HSP students. Of significance, it also found that tertiary students with SPS have often already developed useful metacognitive strategies for independent and life-long learning by the time they reach tertiary level education.
\end{abstract}

\footnotetext{
*Corresponding author: Kaaryn Cater,Whitireia, DX Box: SX33459, 3 Wi Neera Drive, Porirua 5022, New Zealand, Email: Kaaryn.cater@ whitireia.ac.nz
}

Keywords: Highly sensitive person (HSP); Metacognitive strategies; Sensory processing sensitivity (SPS); Ttertiary learning advisors (TLA)

\section{Prologue}

On a Saturday morning in mid-2011, I was listening to the Radio. I have a particularly favourite radio programme I like to listen to on Saturday mornings, hosted by Kim Hill, and consisting of informative and thought-provoking interviews with an array of accomplished and influential international academics and artists. On this particular Saturday morning, Kim Hill was interviewing Dr. Elaine Aron. I was no doubt doing the dishes, or putting the washing in the machine, with half an ear on the radio. Elaine Aron was speaking of her ground-breaking research into sensory processing sensitivity (SPS), and was describing how this manifests itself for people with SPS; people known as Highly Sensitive People (HSP) (E. N. Aron \& Aron, 1997). My interest was piqued. Aron was describing my mother. She was describing me. She was describing my younger son. I grabbed the phone, called my father and told him to listen in. At the conclusion of the interview, I excitedly called my father back, expecting that he would be as excited as I was about the information. He thought it to be a load of old codswallop. I was dumbfounded. How was he not able to see the life-changing relevance of the information we had just been listening to? Easily, as it happens. He belongs to the $80-85 \%$ of the population who is not HSP.

I took the Highly Sensitive Person Scale (HSPS) selftest (E. N. Aron \& Aron, 1997) and scored highly on the test and found the information intriguing. I began researching SPS and purchased Aron's book 'The highly Sensitive Person: How to Survive when the World Overwhelms' 
(Aron, 1996) and Ted Zeff's book 'The Highly Sensitive Person's Survival Guide' (Zeff, 2004). Both Aron and Zeff are psychologists based in California. Aron is the psychologist who first identified SPS and conducted all the initial research in the area, and developed the Highly Sensitive Person Scale (HSPS) (Aron \& Aron, 1997). Zeff specialises in sensitivities in boys and men.

My personal research into SPS gave me a good grounding, and provided clarity around aspects of my own personality I had wondered about, things that made me different in many ways from the majority of people I knew. This new knowledge also led me to view aspects of my students' behaviour in a different light. In particular, I began to look closely at successful students who frequently felt stressed and overwhelmed, and who constantly sought reassurance through individual appointments with me for assignment editing before hand-in. For these students, high-achieving often went hand-in-hand with high levels of overwhelm.

I introduced some students to the concept of SPS and directed some to the HSPS self-test and began to see a pattern emerging. The students who displayed high levels of stress and overwhelm tended to score highly on the HSP self-test. I wondered if it would be helpful to provide information about SPS generally through the institution, but decided I needed first to establish whether an understanding of SPS is useful to students who identify as HSP. Ethics approval was granted and my study 'Does an understanding of HSP help students who identify as Highly Sensitive People (HSP) to manage their learning?' was undertaken. I have shared my findings nationally and internationally, and have had the privilege to meet with both Elaine Aron and Ted Zeff, both of whom are fully supportive of my work.

\section{The back-story}

Sensory processing sensitivity (SPS) is a personality construct that was first identified and described by American psychologist Elaine Aron (Aron \& Aron, 1997). It is seen as an innate personality trait responsible for processing in-coming internal (pain and hunger) and external (light and noise) sensory stimulation that is found in $15-20 \%$ of the population (Aron \& Aron, 1997, Aron, Aron, \& Jagiellowicz, 2012; Boterberg \& Warreyn, 2016).

The trait has been identified in over a hundred species (Smolewska, McCabe, \& Woody, 2006), and the resulting sensitive nervous system is thought to be a genetic sensitivity that may contribute to species survival (Aron \&
Aron, 1997). In the human population, those with SPS are referred to as Highly Sensitive People (HSP) (Aron \& Aron, 1997). HSPs are more reactive to physical, environmental, emotional and social stimuli and have narrower comfort thresholds than the majority of the population (Aron \& Aron, 1997; Aron et al., 2012).

HSPs are also more aware of subtleties in the external and internal environment and tend to process things deeply (Aron \& Aron, 1997; Aron et al., 2012; Jagiellowicz, 2012). Zeff refers to 'a highly tuned nervous system' (Zeff, 2004; p.11). Although Aron did not make explicit the role of emotional reactivity in her original findings on HSP, she now acknowledges the fundamental nature of emotional reactivity to the trait. Further, Baumeister, Vohs, DeWall, \& Zhang, (2007) believe that emotional reactivity is helpful for memory and learning through providing vital feedback that facilitates introspection, and helps to guide behaviour in both novel and similar situations.

HSP can be identified in a human population by the Highly Sensitive Person Scale (HSPS), a 27 point self-test which measures responses to general and subtle environmental and internal stimulation (Aron \& Aron, 1997; Aron et al., 2012; Sobocko \& Zelenski, 2015). The HSPS was designed by Aron as a result of hundreds of complex interviews, and remains in use today, despite substantial scrutiny since its inception in 1997 (Sobocko \& Zelenski, 2015). Aron developed the scale as a unidimensional construct designed to be independent of emotionality, introversion and gender bias to measure environmental, physical and emotional sensitivities. The HSPS is comprised of face value items such as 'Do you startle easily with loud noise?'; 'Are you overwhelmed by strong sensory input?'; 'Are you easily overwhelmed by bright lights, strong smells, course fabrics or sirens close by?'; 'Are you conscientious?'; 'Are you deeply moved by arts or music?'.

Sobocko \& Zelenski, (2015) highlight that the HSPS has been the subject of rigorous scrutiny and Smolewska et al. (2006a) propose a three factor structure with separate subgroups rather than a unidimensional construct. They propose the following subgroups: ease of excitation (EOE); low sensitivity threshold (LST); and aesthetic sensitivity (AES).

Studies conducted by Smolewska et al. (2006a) explored possible correlations between SPS and Behaviour Inhibition System and Behaviour Activation System (BIS/ BAS) and the Big Five, with a focus on neuroticism and extraversion. It was as a result of this work that they identified the three subgroups. The 12 items included in the EOE subgroup show mental overwhelm as a result of external and internal stimulation, for example, "Do you tend to be more sensitive to pain?”, "Do you startle easily?". The 
LST subgroup includes six items that measure unpleasant arousal of external stimuli for example "Are you made uncomfortable by loud noises?", "Do you make a point to avoid violent movies and TV shows?”. The AES subgroup includes seven items measuring aesthetic sensitivities, for example: 'Are you deeply moved by arts or music?', "Do you seem to be aware of subtleties in your environment?”. Two items were not included in any subgroup as they loaded on more than one component "Are you easily overwhelmed by strong sensory input?" and "Does your nervous system sometimes feel so frazzled that you have to get off by yourself?".

Smolewska et al. (2006a) conclude that SPS is not associated with neuroticism, as negative emotionality is associated only with the EOE subgroup. They note that this negative emotionality is associated only with stress and worry and not aesthetic appreciation or deep information processing; and that negative emotionality is not associated with AES or LST. They found that high BIS correlates relatively highly with EOE, and conclude that most inhibition is associated with reducing excitation. In addition, they found that EOE showed a degree of correlation with neuroticism, although the HSPS relates only moderately to neuroticism.

This supports Aron's findings that 30 percent of HSPs are extroverts (Aron \& Aron, 1997). Openness was the only personality factor found to be associated with HSP, and Smolewska et al. (2006a) note that given that HSPs are likely to rate highly for BIS, the tension created between openness and high scoring BIS could lead to overwhelm. They also found that AES correlated slightly with openness and suggested that HSPs with high AES and LST scores could be responsive to incentive and could possibly experience more positive effects when responding to positive stimuli. They conclude that the positive correlations among the factors are consistent with a higher-order construct of SPS and go on to suggest that there is a need for more research in order to inform this relatively new branch of knowledge. This is consistent with my findings that a degree of student overwhelm at tertiary level can be attributed to SPS, although there is a dearth of evidence relating SPS to teaching and learning.

According to Aron, HSPs tend to process things more deeply than others, and for this reason, may take longer to process new information (Aron \& Aron, 1997). I observed that in an educational setting, this may present as an apparent lack of understanding of new information, or falling behind with work. This can lead to further levels of overwhelm that can impact on all areas of health and wellbeing. Further, Jaeger, (2004) asserts that HSPs stay connected with work when it is meaningful, and conversely, are likely to lose interest when work is seen as mundane. This resonates with my observation of student behaviour, and through conversations with HSP students who can lose themselves in flow for 'meaningful' tasks, but often find it extremely difficult to motivate themselves to undertake 'mundane' tasks.

Taking longer to assess information has been referred to by Gray, (1991) in relation to Behaviour Inhibition System (BIS) as 'Stop, look, listen and be ready for action' (p. 110). 'Pause to Check' is a term used to describe the behaviour of observing and processing before acting (Acevedo et al., 2014; Aron \& Aron, 1997; Aron et al., 2012). It is thought that this taking time to evaluate may allow more elaborate processing of information and lead to deeper learning from experience and applying to future experiences (Acevedo et al., 2014). Baumeister et al. (2007) purport that this is a result of cognitive emotional reactivity.

Acevedo et al. (2014) conducted a study using fMRI to observe differences in brain activity between high and low scoring individuals on the HSPS. Although the researchers were looking primarily at participants' reactions to others' emotions, their findings are educationally significant. They found that the areas of the brain that were active in high HSP scoring individuals were those associated with attention and planning for action: imitation learning; intuition; and understanding other people's goals, motives and intentions (Acevedo et al., 2014). In other words, metacognitive awareness.

According to Acevedo et al. (2014), knowledge about SPS is still evolving, and there is growing evidence of social advantages of sensitivity. In a study conducted by Gregory, Nettelbeck, \& Wilson (2010) exploring the relationship between openness to experience, intelligence and successful aging, it was found that there is a link between openness, intelligence and memory. Smolewska et al. (2006a) also concluded that there are distinct advantages to sensitivity, and drew a link between openness and SPS. Although SPS can lead to some challenges of overwhelm, the positive aspects of sensitivity can be seen as useful for life-long learning (Gregory et al., 2010; Smolewska et al., 2006a).

\section{The context}

The role of the tertiary learning advisor (TLA) is complex and varied (Fraser, Manalo, \& Marshall, 2010). MozzonMcPherson, (2007) believes that the primary role of a learning advisor is to help students to develop effective learning behaviours and strategies and this view is 
corroborated by Stickler (2001); in other words, developing metacognitive skills and strategies. These skills are seen as separate from those delivered by the subject tutor who focuses on content (Mozzon-McPherson \& Vismans, 2001; Morrison \& Navarro, 2012).

The importance of developing metacognitive skills in order for successful learning to take place has been well researched and documented since the 1980s. The early work of researchers such as Flavell, (1979); and Biggs, (1988) laid the foundation for later work, such as that of Pintrich (2000) who asserts that metacognition is a myriad of skills including knowledge, judgement, monitoring and self-regulation. These are skills that are necessary for autonomous and life-long learning.

Boud, (2012) argues that students are unlikely to develop the skills necessary for autonomous and life-long learning if they are primarily driven by grades, and yet, by the nature of tertiary study, grades remain vital. Subject tutors teach content, and TLAs teach process, or metacognitive skills and strategies (Biggs, 1988). Wilkinson, Bowker, Deane-Freeman, \& Rullan, (2008) note that there is likely to be some tension between providing specific assignment-related content rather than considering the questions of broader metacognitive skills. I have observed this tension with students who often attend individual appointments primarily for the purpose of proof-reading, and may not be particularly receptive to discussion of broader metacognitive skills.

Morrison \& Navarro, (2012) highlight the myriad metacognitive skills TLAs promote, including: initiating, goal setting, guiding, modelling, supporting, giving feedback, linking, concluding, initiating, attending, restating, paraphrasing, summarising, questioning, interpreting, reflecting feelings, empathising, and confronting. Imel, (2002) states that tutors displaying a high sense of awareness of their own metacognitive skills and strategies can play a significant role in guiding students toward metacognitive understandings. Imel (2002) and Rivers (2001), go on to point out that self-management skills are key components in the work of TLAs.

Fraser, Manalo, \& Marshall, (2010) assert that individual TLA consultations are, by their nature, customised to the needs of the specific student, with the focused teaching resulting in "some rich eureka moments" (p. 74). It is precisely this customisation that leads to the unique relationship I, and my TLA colleagues, are able to form with students. Fraser et al., (2010) also note that TLAs are better placed than content tutors to provide counselling. Although counselling is not considered a primary role of TLAs, it never-the-less forms part of the interactions TLAs have with individual students due to the complexity of the interactions (Stickler, 2001). TLAs, therefore, are often able to spend considerable time with students on an individual basis, and are able to observe student behaviour that may go unnoticed in the classroom or by tutors and peers. Having the opportunity to sit together and chat informally is an important aspect of my relationship with students, and the foundation of a trusting partnership.

Tertiary students are more likely to succeed in their studies when they have a strong and supportive relationship with their tutors (Gerdes \& Mallinckrodt, 1994; Johnson, 1995). Gerdes \& Mallinckrodt (1994) also note that first year tertiary students in particular are likely to struggle socially, emotionally and academically as they adjust to their new surroundings. Further, McInnis \& James, (1994) assert that first year tertiary students are likely to struggle with learning autonomously, and conclude that institutions need to do more to help students cope with transitioning into tertiary environments. According to Fraser et al., (2010), TLAs are more likely to see first year students in individual sessions, and are therefore likely to build strong relationships with these students that may continue through the duration of their study. Often students form enduring relationships with TLAs, after meeting in the first year, and I have noted that HSP students are more likely than non-HSP students to form these close relationships that span the duration of their study.

TLAs are able to form close relationships with students during individual consultations (Carter, 2009; Morrison \& Navarro, 2012). Further, Morrison \& Navarro, (2012) refer to the 'therapeutic dialogue' that takes place between advisor and student, and stress the responsive nature of the relationship. Wilkinson et al. (2008) speak of TLAs empowering the student voice through relationship-building and clear communication.

Therefore, it can be argued that TLAs operate at the syntheses of relationship and skills-building, and are therefore in a strong position to connect with students and observe student behaviour and learning strategies.

\section{The script}

Over several years of working closely with students both in the classroom, and individually, I observed a range of behaviours in students that were not consistent with any empirical knowledge I was aware of. Such behaviours included otherwise successful students falling behind with work while becoming overwhelmed, stressed and anxious about managing work-load and completing 
academic tasks. I hypothesised that a possible explanation for the observed student difficulties could, in part, be due to aspects of sensory processing sensitivity.

The original motivation for the Whitireia research was based on the hypothesis that there could be issues related to teaching and learning for HSP students in the tertiary setting. I decided to initially establish whether students found it useful to know about SPS and HSP. Ethics approval was granted to conduct the study: "Does an understanding of HSP help students who identify as HSP to manage their learning?"

\section{Method and data collection}

A mixed method approach was deemed the most appropriate for this study in order to build extensive demographic and quantitative data and to allow for the complexity of qualitative data collected through interviews. The original HSPS responses provided quantitative data that provided information on the specific responses made by each participant. I decided to use the simplified HSPS (Aron \& Aron, 1997) in preference to the more complicated research scale which includes Likert ratings for each question, as the research question was simply looking to establish whether students found the information useful, and comparative analysis was not planned.

Using the initial HSPS scorings, I decided to take 12 as the cut-off score, and all students scoring 12 or higher on the HSPS were invited to take part in a semi-structured interview which included four major questions relating to life and study. Students were first asked to rate growing up, school, tertiary study and managing life/study balance on a six point Likert scale in order to elicit quantitative values. The interviews progressed according to each student's Likert rating for each question.

Interviews were conducted in a collaborative way, and students were informed that they were under no obligation to answer all questions, and were free to terminate the interview at any time. All interviewed students chose to answer all questions. Extensive qualitative data were collected at this point. At the conclusion of the first interview, students were given an HSP information pack which included information and resources pertaining to SPS. A follow-up interview was scheduled for several weeks later, at which point students were asked to rate the usefulness of an awareness of HSP, and the information and resources provided.

\section{Participants}

A convenience sample of 179 Whitireia students was asked to complete the HSPS self-evaluation. Of these students, 134 elected to complete the questionnaire, 80 of whom identified as HSP according to the HSPS 12 or higher score threshold. 34 students chose to continue on with the interview. Of these 34 students, 21(62\%) were female and $13(38 \%)$ were male. They ranged in age from 18-53 years. 23 participants (68\%) identified as New Zealand Pakeha (New Zealanders of European descent), three identified as New Zealand Māori (indigenous people of New Zealand), with the remaining eight participants of mixed ethnicity (One English, one Chinese, one African, and five of mixed or unstated ethnicity).

\section{Data analysis}

Of the 134 students who chose to complete the HSPS, 80 students identified as HSP according to a score of 12 or higher on the HSPS ( $60 \%$ of the participating students). The most commonly checked item for the 80 students was in answer to the question "Do other people's mood affect you?"(70 students); the second most commonly checked item was "are you conscientious?"(62 students); with the third most commonly checked item was "Are you annoyed when people try to make you do too many things at once?" (61 students). The fourth most commonly checked item was "Do you get rattled when you have a lot to do in a short amount of time?" (60 students).

Of the 80 who identified as HSP, 34 elected to take part in the initial interview (43\%). 25 students (74\%) completed both interviews, and of those 25 students, 100\% rated the knowledge of HSP to be useful in managing life and study ( 6 on the 6 point Likert scale). All students completing the second interview rated the information pack to be moderately helpful (mean score of 4.5 on the 6 point Likert scale). The volume of qualitative data collected is extensive and can be analysed in a myriad of ways.

Overall reactions to HSP awareness have been correlated in order to answer the research question. When asked for personal reactions to knowing about HSP, students responded in such ways: "Wow! I feel normal!"; "Knowing about HSP has helped me to deal with things better and build up ways to make me stronger as a person."; "So good to know what's going on!"; "Thank you. I can forgive myself."; "This helps me to deal with ongoing stresses!”; "Now I know what I have to do!”; "Thank you. This changes everything."; "Without you I 
would hang out in the world like a ghost, but thanks to you I am not a ghost anymore".

Of significance, all students who completed the second interview, in answer to the question "What can Whitireia do to help students and tutors to know about HSP?" responded that they thought that the institution should make information about HSP available to all in-coming students and all tutors.

\section{Discussion}

Given that $100 \%$ of second interview respondents state that knowledge of HSP is not only useful, but life-changing, and that they think that information about SPS and HSP should be available to students and tutors, there needs to be discussion at the institutional level about how best to provide information and make it available for staff and students. There would need to be buy-in from executive level, and information and training would need to be provided for tutors. Aron \& Aron (1997) assert that 15-20\% of the general population is HSP and it would be expected, therefore, that a similar percentage would be present in the convenience sample used in this study. However, $60 \%$ of the original participants in this study identified as HSP. There could be a number of factors contributing to this higher than expected percentage.

It could be that the threshold of 12 on the HSPS was too low. I hypothesised that if this were the case, there would be a large differential between the mean scores of the original 80, and of those who chose to follow through with the interview. I found that the mean score for the initial 80 participants was 17.26 , and the mean score for the 39 interviewed participants was 18.22. The low threshold, therefore, may have had a moderate impact on the higher than anticipated number of identifying HSPs. In addition, the majority of students (78\%) who took part in this study were arts students and this could have increased the percentage of students identifying as HSP. There is a case for further research on actual numbers of HSPs at the institution, with a break-down according to specific programmes.

I decided it would be useful to apply the three subgroups as identified by Smolewska et al. (2006a) to the four most commonly checked items. First, "Do other people's mood affect you?"(87.5\%) (EOE); the second most commonly checked item, "Are you conscientious?"(77.5\%) (AES); the third most commonly checked item, "Are you annoyed when people try to make you do too many things at once?" (76.2\%) (EOE); with the fourth, "Do you get rattled when you have a lot to do in a short amount of time?" (75\%). Three of the top four items belong to the EOE subgroup, as identified by Smolewska et al. (2006a). This is not surprising, given that the 12 items included in EOE measure mental overwhelm as a result of internal or external stimulation. Of significance, it is others' moods that appears to be the most overwhelming for students. This would indicate that a tutor's demeanor and the overall harmony of the classroom plays a significant role in the comfort level of HSP students.

The second most commonly checked item 'Are you conscientious?', although categorised as AES can be seen as a pull between BIS and openness. Students want to do well, but may find it difficult processing new information, which leads to feelings of overwhelm. Finally, it is significant that $76.2 \%$ of students reported that they get annoyed when people try to make them do too many things at once. While it is not surprising that students will tend to become stressed and overwhelmed when faced with multiple concurrent tasks, it is worth noting that this is of particular distress to HSP students. These findings are useful for exploring how best to support HSP students.

In order to do so, institutional and executive buy-in is necessary to drive policy and procedures. In particular, there needs to be rigorous intuitional guidelines requiring all programmes to spread work-load evenly throughout the academic year, so as not to overload students and cause overwhelm. In addition, it is imperative for HSP students to receive feedback on their work in a timely manner, as feedback provides a vital component in developing deep learning that is used to apply new knowledge to new situations (Baumeister et al., 2007).

I had hypothesised that the information pack would be of high value to students, but the findings showed it to be of moderate value. It could be further hypothesised from this that by the time HSP students are attending tertiary education, they have already developed useful metacognitive strategies that allow them to navigate their sensitivities. This is consistent with the findings of Zeff, (2004), Smolewska et al. (2006a), and Gregory et al. (2010); all of whom have identified distinct metacognitive advantages to sensitivity.

\section{Limitations}

The major limitation of this study was the initial timing. Students were invited to participate in the fourth term of the academic year. Not only were students busy with end of year exams and assignments, they were reluctant to 
return to campus once they had completed their studies for the year. Future research would benefit from commencing at the beginning of the year in order to allow time to complete the study. Self-selection bias may be seen as a limitation of this study, and future research could employ other methods to enlist participants. The data collection was extremely time-consuming, and future studies would benefit from an on-line platform. Limited ethnic diversity can be seen as a limitation.

\section{Epilogue}

There is a paucity of research into the impact of SPS on teaching and learning. Given that all participants in the second interview of this study suggested that information be made available to all in-coming students, there is evidence that further research is needed. In addition, anecdotally, I have noticed that many of the students who identified as HSP experienced periods of physical ill-health, and this is consistent with Aron's findings (E. N. Aron \& Aron, 1997). Future research could include questions relating to physical health. In addition, I have noted that HSP students are more likely to seek on-going validation of their work from others, and research into this could be useful. Further research into the three subgroups as they relate to success in tertiary study could be useful. Given that sensitivity is valued differently culturally, a useful area for research would be some cross-cultural studies comparing the international HSP student experience.

In February 2017, all first-year degree students at our institution will be offered the opportunity to take part in a three year longitudinal study exploring a variety of areas that may impact on student success, including the degree to which the SPS subgroups, as identified by Smolewska et al. (2006a), can be seen as a help or hindrance in tertiary study. Not only are we embarking on an exciting project, the aim of which is to establish ways to best support HSP students and students with minority forms of information processing, but we are also providing the information on SPS that our HSP students requested of us.

\section{Post-Script: The transformation}

The past five years have been a journey of discovery of self, and through that, a journey of discovery for the many students who have come to understand that their differences are not due to deficits or pathologies, but are simply the result of a minority form of information processing. Given that HSPs are in the minority, there will always be non-HSPs, the majority, who may question the validity of the science. Like the self-reported important psychologist who listened to me give a presentation about HSP and hijacked the Q\&A by claiming I was talking about introverted neuroticism. Or the person who attended another presentation I gave, and wanted to know where I scored on the HSPS, hoping to establish that my findings were biased. Or the glazed looks of people who hear white noise and are sorry they asked when I explain about my research. These people are the $80-85 \%$ majority who are not HSP. What of the HSP students? What of the other HSPs I meet along the way? Our lives have all been transformed through the knowledge of SPS. And what of my father? He's pretty proud of his daughter, and is happy to speak at length to anyone who asks about my work and SPS. Our stories have changed forever.

\section{References}

[1] Acevedo, B. P., Aron, E. N., Aron, A., Sangster, M. D., Collins, N., \& Brown, L. L. (2014. The highly sensitive brain: An fMRI study of sensory processing sensitivity and response to others' emotions. Brain and Behavior, 4(4), 580-594. https://doi. org/10.1002/brb3.242

[2] Aron, E. (1996). The highly sensitive person: How to thrive when the world overwhelms you (Rev. ed.). GEN, New York: Broadway Books

[3] Aron, E. N., \& Aron, a. (1997). Sensory-processing sensitivity and its relation to introversion and emotionality. Journal of Personality and Social Psychology, 73(2), 345-368. https://doi. org/10.1037/0022-3514.73.2.345

[4] Aron, E. N., Aron, a., \& Jagiellowicz, J. (2012). Sensory Processing Sensitivity: A Review in the Light of the Evolution of Biological Responsivity. Personality and Social Psychology Review. 16(3), 262-282. https://doi. org/10.1177/1088868311434213

[5] Baumeister, R. F., Vohs, K. D., DeWall, C. N., \& Zhang, L. (2007). How emotion shapes behavior: feedback, anticipation, and reflection, rather than direct causation. Personality and Social Psychology Review: An Official Journal of the Society for Personality and Social Psychology, Inc, 11(2), 167-203. https:// doi.org/10.1177/1088868307301033

[6] Biggs, J. (1988). The role of metacognition in enhancing learning. Australian Journal of Education, 32(2), 127-138

[7] Boterberg, S., \& Warreyn, P. (2016). Making sense of it all: The impact of sensory processing sensitivity on daily functioning of children. Personality and Individual Differences, 92, 80-86. https://doi.org/10.1016/j.paid.2015.12.022

[8] Boud, D. (Ed.). (2012). Developing student autonomy in learning. Routledge

[9] Carter, S. (2009). The shifting sands of tertiary individual consultation. presented at the meeting of the Shifting 
sands, Firm foundations: Proceedings of the 2009 Annual International Conference of the Association of Tertiary Learning Advisors of Aotearoa/New Zealand, Auckland

[10] Flavell, J. H. (1979). Metacognition and cognitive monitoring: A new area of cognitive - developmental inquiry. American Psychologist, 34(10), 906-911

[11] Fraser, C., Manalo, E., \& Marshall, J. (2010). Many and varied roles: An inter-institutional project to evidence the impact of learning advisors on student achievement. In Shifting sands, firm foundations: Proceedings of the 2009 association of tertiary learning advisors of Aotearoa New Zealand conference (pp. 31-44)

[12] Gerdes, H., \& Mallinckrodt, B. (1994). Emotional, social, and academic adjustment of college students: A longitudinal study of retention. Journal of Counseling and Development: JCD, 72(3), 281

[13] Gray, J. A. (1991). The neuropsychology of temperament. In J. Strealau Explorations in temperament (pp. 105-128). Springer US

[14] Gregory, T., Nettelbeck, T., \& Wilson, C. (2010). Openness to experience, intelligence, and successful ageing. Personality and Individual Differences, 48(8), 895-899. https://doi. org/10.1016/j.paid.2010.02.017

[15] Imel, S. (2002). Metacognitive Skills for Adult Learning. Trends and Issues Alert

[16] Jaeger, B. (2004). Making work work for the highly sensitive person. McGraw-Hill

[17] Jagiellowicz, J. A. (2012). The relationship between the temperament trait of sensory processing sensitivity and emotional reactivity

[18] Johnson, B. M. (1995). Why Conduct Action Research?. Teaching and Change, 3(1), 90-104

[19] McInnis, C., \& James, R. (1994). Gap or gulf. Students' Perspectives on the Transition to University in Australia

[20] Morrison, B. R., \& Navarro, D. (2012). Shifting roles: From language teachers to learning advisors. System, 40(3), 349-359. https://doi.org/10.1016/j.system.2012.07.004
[21] Mozzon-McPherson, M. (2007). Supporting independent learning environments: An analysis of structures and roles of language learning advisers. System, 35(1), 66-92

[22] Mozzon-McPherson, M., \& Vismans, R. (2001). Beyond language teaching towards language advising. BOOK, Centre for Information on Language Teaching and Research

[23] Pintrich, P. R. (2000). The role of motivation in self-regulated learning. Conative Constructions and Self-Regulated Learning, 51-66

[24] Rivers, W. P. (2001). Autonomy at All Costs: An Ethnography of Metacognitive Self-Assessment and Self-Management among Experienced Language Learners. The Modern Language Journal, 85(2), 279-290

[25] Smolewska,, K. A., McCabe, S. B., \& Woody, E. Z. (2006). A psychometric evaluation of the Highly Sensitive Person Scale: The components of sensory-processing sensitivity and their relation to the BIS/BAS and "Big Five." Personality and Individual Differences, 40(6)

[26] Sobocko, K., \& Zelenski, J. M. (2015). Trait sensoryprocessing sensitivity and subjective well-being: Distinctive associations for different aspects of sensitivity. Personality and Individual Differences, 83, 44-49. https://doi.org/10.1016/j. paid.2015.03.045

[27] Stickler, U. (2001). Using counselling skills for language advising. In: Mozzon-McPherson, Marina and Vismans, Roel eds. Beyond language teaching towards language advising. London: CILT, pp. 40-52

[28] Wilkinson, L., Bowker, N., Deane-Freeman, J., \& Rullan, S. (2008). What students request versus what we deliver: Balancing learning skills and academic acculturation. In 2007 Annual International Conference of the Association of Tertiary Learning Advisors of Aotearoa New Zealand, Auckland, New Zealand

[29] Zeff, T. (2004). The highly sensitive person's survival guide. Oakland: New Harbinger Publications 